\title{
In vitro Self-organized Mouse Small Intestinal Epithelial Monolayer Protocol
}

Gizem Altay ${ }^{1}$, Eduard Batlle2, 3, 4, Vanesa Fernández-Majada1, \# * and Elena Martinez ${ }^{1,5,6, \#, ~ * ~}$

${ }^{1}$ Biomimetic Systems for Cell Engineering Laboratory, Institute for Bioengineering of Catalonia (IBEC), The Barcelona Institute of Science and Technology (BIST), Barcelona, Spain; ${ }^{2}$ Colorectal Cancer Laboratory, Institute for Research in Biomedicine (IRB Barcelona), The Barcelona Institute of Science and Technology (BIST), Baldiri Reixac 10-12, Barcelona 08028, Spain; ${ }^{3}$ Centro de Investigación Biomédica en Red de Cáncer (CIBERONC), Barcelona, Spain; ${ }^{4}$ ICREA, Passeig Lluís Companys 23 , 08010 Barcelona, Spain; ${ }^{5}$ Centro de Investigación Biomédica en Red (CIBER), Madrid, Spain; ${ }^{6}$ Department of Electronics and Biomedical Engineering, University of Barcelona (UB), Barcelona, 08028 Spain

\#Contributed equally to this work

*For correspondence: emartinez@ibecbarcelona.eu; vfernandez@ibecbarcelona.eu

[Abstract] Developing protocols to obtain intestinal epithelial monolayers that recapitulate in vivo physiology to overcome the limitations of the organoids' closed geometry has become of great interest during the last few years. Most of the developed culture models showed physiological-relevant cell composition but did not prove self-renewing capacities. Here, we show a simple method to obtain mouse small intestine-derived epithelial monolayers organized into proliferative crypt-like domains, containing stem cells, and differentiated villus-like regions, closely resembling the in vivo cell composition and distribution. In addition, we adapted our model to a tissue culture format compatible with functional studies and prove close to physiological barrier properties of our in vitro epithelial monolayers. Thus, we have set-up a protocol to generate physiologically relevant intestinal epithelial monolayers to be employed in assays where independent access to both luminal and basolateral compartments is needed, such as drug absorption, intracellular trafficking and microbiome-epithelium interaction assays. Keywords: Mouse intestinal organoids, Adult intestinal stem cells, Matrigel, Intestinal epithelial monolayer, In vitro intestinal epithelial model, Tissue-like functionality, TEER

[Background] The development of epithelial organoid culture systems is a major scientific achievement that has been established as an important tool in many basic biology and clinical applications due to their similarity in cell composition and function to the in vivo organ. Specifically, intestinal epithelial organoids are spherical formations with budding structures containing stem, Paneth and proliferative cells, corresponding to intestinal crypts, and inter-budding areas of differentiated cells representing the intestinal villi (Sato et al., 2009; Ootani et al., 2009). One of the major drawbacks of the intestinal organoid system is their closed-spherical structure which hampers their use in standard functional assays in which direct access to the organoid lumen or apical site of the epithelium is required. In the last few years, several attempts to open-up the spherical organoids into 2D monolayers have been established (Moon et al., 2014; VanDussen et al., 2015; Ettayebi et al., 2016; In et al., 2016; Kozuka 
et al., 2017). However, the reported epithelial monolayers were mainly composed of mature epithelial cells with poor characterization of the proliferation and self-renewing capacities. More recently, methods to obtain monolayers with both proliferative and differentiated regions have been published. Although showing a physiologically relevant cell composition and distribution, those monolayers did not expand enough to cover the full substrate area and did not allow access to the basolateral site preventing their use in functional assays (Wang et al., 2017a; Liu et al., 2018; Thorne et al., 2018).

Here, we describe an experimental protocol in which we grow either Lgr5-EGFP-ires-Cre ERT2 mouse organoid-derived crypts or single cells on a thin layer of Matrigel to obtain intestinal epithelial monolayers that self-organize in crypt foci, containing stem cells, Paneth and proliferative cells, and villilike regions composed of differentiated cells, resembling the cell distribution found in the in vivo small intestine. Importantly, our results indicate that the capacity of the intestinal epithelial cells to first selforganize into crypt-like domains and then originate villus-like regions is regulated intrinsically and is not due to the preservation of pre-established crypt configuration. We successfully adapted this method to a Transwell inserts culture format, as previously described (Wang et al., 2017b), which allow an independent access to the basolateral and apical compartments, and demonstrate that the basolateral administration of crypt medium supplemented with non-epithelial niche-derived biochemical factors boosted epithelial monolayer expansion to fully cover the tissue culture substrate without altering the crypt-villus-like cell distribution.

These features of our model enable to perform functional assays such as to record transepithelial electrical resistance (TEER) measurements to determine the monolayers' epithelial barrier properties. We found that TEER values were within the expected physiological range $\left(40-100 \Omega \mathrm{cm}^{2}\right)$ for mouse small intestine, demonstrating an adequate maturation of de novo generated epithelium. Overall, we have developed a protocol to generate organoid-derived intestinal epithelial monolayers with in vivo-like structural and functional features in a culture format compatible with functional assays. We believe our technology meet the necessary features of the complex 3D organotypic cell culture systems and $2 \mathrm{D}$ formats for a close to physiological high-throughput testing.

\section{Materials and Reagents}

\section{A. Materials}

1. Petri dishes, $94 \times 16 \mathrm{~mm}$, sterile (Biolab, catalog number: 020005)

2. Glass coverslips $24 \times 24 \mathrm{~mm}$ (Deltalab, catalog number: D102424)

3. Serological pipettes $5 \mathrm{ml}, 10 \mathrm{ml}, 25 \mathrm{ml}$ (Nunc, catalog numbers: 056815, 056816, 056817)

4. Racked filter pipette tips $20 \mu \mathrm{l}, 200 \mu \mathrm{l}, 1,000 \mu \mathrm{l}$, sterile (Labclinics, catalog numbers: LAB20ULFNL, LAB200ULFNL, LAB1000ULFNL)

5. $70 \mu \mathrm{m}$ pore cell strainer (Biologix Research Co., catalog number: 151070)

6. 24-well multiwell plates (Nunc, catalog number: 142485)

7. Falcon, $50 \mathrm{ml}$ centrifuge tubes (Deltalab, Eurotubo, catalog number: DEL429927)

8. Falcon, $15 \mathrm{ml}$ centrifuge tubes (Deltalab, Eurotubo, catalog number: DEL429946) 
9. Ibidi 8-well $\mu$-Slides (Ibidi $\mathrm{GmbH}$, catalog number: 80826)

10. Transwell polycarbonate membrane cell culture inserts, $6.5 \mathrm{~mm}$ diameter, $0.4 \mu \mathrm{m}$ pore size (Corning, catalog number: CLS3413)

11. 23 G 1" needle (BD Microlance 3, catalog number: 300800)

12. Disposable $1 \mathrm{ml}$ syringe (B-Braun, catalog number: $9166017 \mathrm{~V}$ )

13. Disposable $10 \mathrm{ml}$ syringe (Becton Dickonson, catalog number: 309110 )

14. Cell culture flasks, filter cap $25 \mathrm{~cm}^{2}$ (Nunc EasYFlasks, catalog number: 156367)

15. Syringe filter, $0.22 \mu \mathrm{m}$ pore size, sterile (Millipore, Millex, catalog number: SLGP033RS)

B. Reagents

1. Phosphate buffered saline (PBS) powder, $\mathrm{pH} 7.4$ (Sigma-Aldrich, catalog number: $\mathrm{P} 3813$ ), store at RT

2. Ethylenediaminetetraacetic acid (EDTA) solution, $\mathrm{pH} 8.0, \sim 0.5 \mathrm{M}$ (Sigma-Aldrich, catalog number: 03690), store at RT

3. Matrigel Basement membrane matrix, LDEV-free (Corning, catalog number: 354234), store at $-20^{\circ} \mathrm{C}$

Note: Thaw O/N on ice and aliquot in 0.5-1 m/ vials upon arrival, to minimize freeze and thaw cycles.

4. Advance Dulbecco's modified medium (DMEM)/F12 (Thermo Fisher Scientific, Gibco, catalog number: 12634010$)$, store at $2-8^{\circ} \mathrm{C}$

5. GlutaMAX supplement, 100x (Thermo Fisher Scientific, Gibco, catalog number: 35050038), store at $2-8{ }^{\circ} \mathrm{C}$

6. 4-(2-hydroxyethyl)-1-piperazineethanesulfonic acid (HEPES) buffer solution, $1 \mathrm{M}$ (Thermo Fisher Scientific, Gibco, catalog number: 15630056), store at $2-8{ }^{\circ} \mathrm{C}$

7. Normocin (InvivoGen, catalog number: ant-nr-2), store at $-20^{\circ} \mathrm{C}$

8. B-27 supplement, minus vitamin A, 50x (Thermo Fisher Scientific, Gibco, catalog number: 12587010), store at $-20^{\circ} \mathrm{C}$ aliquoted

9. N-2 supplement, 100x (Thermo Fisher Scientific, Gibco, catalog number: 17502048), store at $-20{ }^{\circ} \mathrm{C}$ aliquoted

10. N-Acetyl-L-cysteine (Sigma-Aldrich, catalog number: $\mathrm{A} 9165$ ), store at $-20{ }^{\circ} \mathrm{C}$ aliquoted

11. Recombinant murine Epidermal growth factor (EGF) (Thermo Fisher Scientific, Gibco, catalog number: PMG8043), store at $-20^{\circ} \mathrm{C}$ aliquoted

12. Recombinant human R-spondin 1 (R\&D Systems, catalog number: 4645-RS-250), store at $-20^{\circ} \mathrm{C}$ aliquoted

13. Recombinant murine Noggin (Peprotech, catalog number: $250-38$ ), store at $-20^{\circ} \mathrm{C}$ aliquoted

14. Y-27632 Dichloride, powder (Sigma-Aldrich, catalog number: $\mathrm{Y} 0503$, reconstitute at $1 \mathrm{mM}$ in sterile Milli- $Q$ and store at $-20{ }^{\circ} \mathrm{C}$ aliquoted)

15. CHIR99021 (Stemgent, catalog number: 04-0004), store at $-20^{\circ} \mathrm{C}$ aliquoted

16. Valproic acid sodium salt (Sigma-Aldrich, catalog number: $\mathrm{P} 4543$, reconstitute at $1 \mathrm{M}$ in sterile 
Milli-Q and store at -20 aliquoted)

17. TrypLE Express enzyme, with phenol red, $1 x$ (Thermo Fisher Scientific, Gibco, catalog number: 12605010), store at $2-8^{\circ} \mathrm{C}$

18. Fetal bovine serum (FBS), heat inactivated (Thermo Fisher Scientific, Gibco, catalog number: 10500064), store at $-20^{\circ} \mathrm{C}$

19. DMEM, high glucose, GlutaMAX supplement, pyruvate (Thermo Fisher Scientific, Gibco, catalog number: 31966021$)$, store at $2-8^{\circ} \mathrm{C}$

20. Penicillin-streptomycin, with 10,000 units penicillin and $10 \mathrm{mg}$ streptomycin per $\mathrm{ml}$ in $0.9 \% \mathrm{NaCl}$ (Sigma-Aldrich, catalog number: P0781), store at $-20^{\circ} \mathrm{C}$

21. Minimum essential medium non-essential amino acid (MEM-NEA) solution, 100x (Thermo Fisher Scientific, Gibco, catalog number: 11140035), store at 2-8 ${ }^{\circ} \mathrm{C}$

22. Collagenase (Sigma-Aldrich, catalog number: C0130), store at $-20^{\circ} \mathrm{C}$

23. ACK Lysing Buffer (Gibco, catalog number: A10492-01), store at RT

24. Ethanol, 96\% v/v (PanReac Applichem, catalog number: 131085), store at RT

25. Intestinal organoid growth medium or ENR_CV medium (see Recipes section, Table 1)

26. Intestinal subepithelial myofibroblast digestion medium (see Recipes section, Table 2)

27. Intestinal subepithelial myofibroblast culture medium (see Recipes section, Table 3)

28. Boosting medium (see Recipes section, Table 4)

29. Basic-medium (see Recipes section, Table 5)

30. $70 \%$ v/v Ethanol (see Recipes section, Table 6)

\section{Equipment}

1. Surgical tweezers (Biolab, catalog numbers: 711198 and 711199)

2. Surgical scalpel (Paramount, catalog number: PCS23)

3. Surgical scissors (Biolab, catalog number: 005064)

4. $37^{\circ} \mathrm{C}$ water bath (Fisher Scientific, Polytest 20 )

5. Milli-Q water purification system (Millipore, $Q-P O D)$

6. Neubauer counting chamber (BRAND, catalog number: 718605)

7. Micropipettes (Gilson, models: P20, P200, P1000)

8. Pipette aid (Eppendorf, Easypet)

9. Cell culture benchtop centrifuge (Beckman Coulter, model: Allegra X-12R)

10. $37^{\circ} \mathrm{C}$ humidified incubator with $5 \% \mathrm{CO}_{2}$ (Thermo Scientific, Steri-Cult 3141)

11. Laminar flow hood (Telstar, BIO II A)

12. Platform Shaker (Heidolph, model: Unimax 1010)

13. Incubated benchtop orbital shaker (Thermo Scientific, 4518 S/N 15150-131)

14. Bright field microscope (Nikon, Eclipse Ts2)

15. Epithelial voltohmmeter with STX3 electrodes (World Precision Instruments, EVOM2)

16. Ice machine (Scotsman, MF56) 


\section{Procedure}

A. Intestinal crypt isolation and culture (Figure 1A)

Note: Perform until Step A8 on the bench and from then onwards you might continue the protocol under a laminar flow hood to favor sterility.

\section{Overview of in vitro intestinal epithelial monolayer protocol}
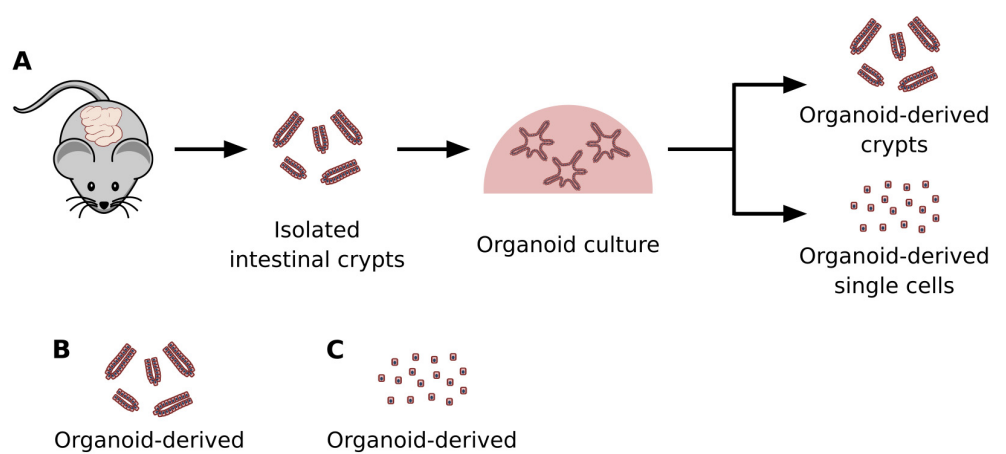

C

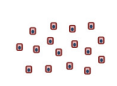

Organoid-derived

crypts

single cells
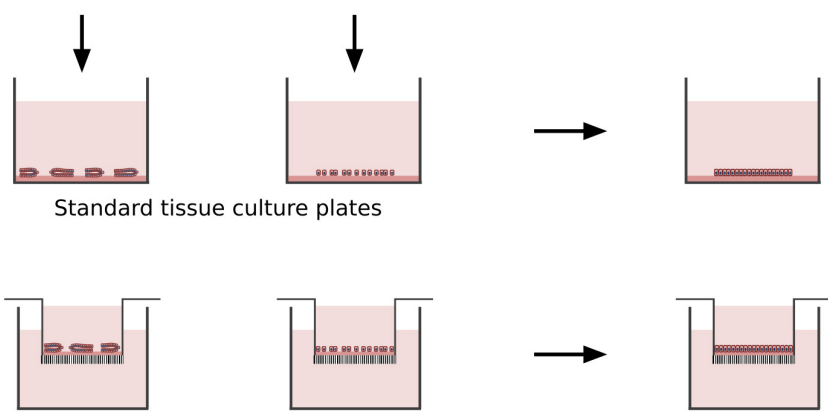

Transwell inserts

Seeding on Matrigel-coated substrates

$2 \mathrm{D}$ in vitro intestinal epithelial culture systems

Figure 1. Overview of the developed methodology for the generation of in vitro intestinal epithelial monolayer. A. Intestinal crypts are isolated from Lgr5-EGFP-IRES-creERT2 mouse and grown in Matrigel drops to obtain the organoid culture. Organoids are dissociated into $B$. crypt pieces or $\mathrm{C}$. single cells and seeded on Matrigel coated standard tissue culture plates or Transwell inserts to obtain a 2D in vitro intestinal epithelial culture system.

1. Harvest the small intestine from Lgr5-EGFP-IRES-creERT2 mouse.

2. Place the intestine into a Petri dish with PBS and remove the fat and mesentery from the tissue using surgical tweezers and a scalpel or surgical scissors.

Note: Be careful not to rupture the intestinal tissue.

3. Flush the mouse small intestine with PBS using a $10 \mathrm{ml}$ syringe and a $23 \mathrm{G} 1$ " needle.

4. Cut up the tissue longitudinally using surgical scissors.

Note: Make sure that when you cut open the tissue the mucosal side is facing upwards.

5. Remove the villi mechanically by scraping carefully the intestinal mucosa with a glass coverslip. 
Note: Be careful not to apply too much pressure to preserve the crypts.

6. Rinse 3 times with PBS and place the intestine into a new Petri dish.

7. Cut the tissue into pieces of 1-4 mm thick using surgical scissors (see Figure 2).

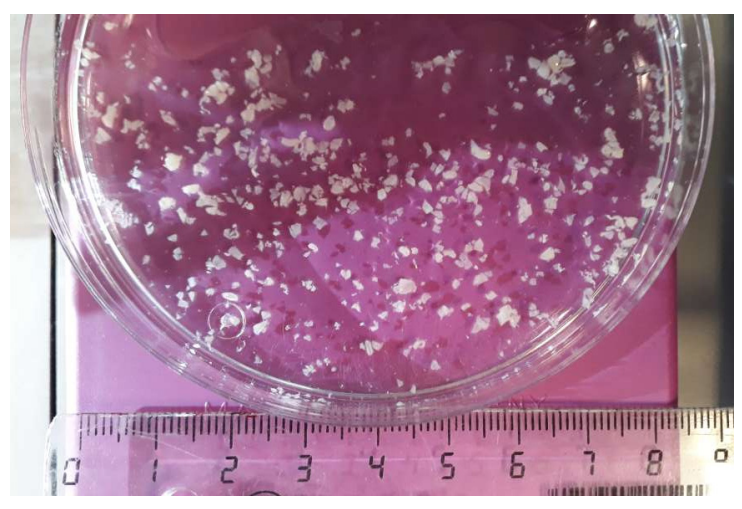

Figure 2. Picture showing the appearance (size and shape) of the tissue pieces obtained after cutting the intestine using surgical scissors.

8. Transfer the pieces into a sterile $50 \mathrm{ml}$ Falcon tube under the laminar flow hood.

9. Add $10 \mathrm{ml}$ ice-cold PBS and pipette up and down 5-6 times using a $10 \mathrm{ml}$ pipette. Let the pieces settle and discard the supernatant.

Note: It is very important that the PBS is ice cold and that the inner pipettes walls are previously wetted with PBS. If not, the tissue pieces might stick to the pipette.

10. Add fresh $10 \mathrm{ml}$ ice-cold PBS and repeat the Step A9 for 10-20 times until the supernatant becomes almost clear.

Note: The supernatant might still be a bit cloudy after 20 washes, proceed with the next step anyways.

11. Add $25 \mathrm{ml}$ of $2 \mathrm{mM}$ EDTA prepared in cold PBS and incubate it for $30 \mathrm{~min}$ at $4{ }^{\circ} \mathrm{C}$. Agitate vigorously the Falcon tube during incubation on a platform shaker.

12. After the incubation, let the tissue pieces settle to the bottom of the Falcon tube and discard the supernatant.

13. Add $10 \mathrm{ml}$ of ice-cold PBS with $10 \%$ FBS to the tissue pieces using $10 \mathrm{ml}$ pipette. It is recommended to wet the inner wall of the pipette with ice cold-PBS with $10 \%$ FBS to avoid tissue pieces sticking to the pipette.

14. Pipette up and down 3-5 times the tissue pieces using a $10 \mathrm{ml}$ pipette. Let the pieces to settle down and filter the supernatant through a $70 \mu \mathrm{m}$ pore cell strainer placed on top of a new $50 \mathrm{ml}$ Falcon tube. The eluted solution will correspond to the first crypt elution fraction.

15. Repeat the Steps A13 and A14 for 4-5 times more to obtain the following crypt elution fractions. Use new $70 \mu \mathrm{m}$ pore cell strainers and new $50 \mathrm{ml}$ Falcon tubes to collect the subsequent crypt elution fractions.

16. Pipette $5 \mu \mathrm{l}$ of each of the eluted fractions in a Petri dish and analyze them using a bright field microscope, to determine the purity and the size of the crypts in each fraction. 
Note: Usually, the first fractions contain a lot of debris and some villi pieces. It is advisable to discard these fractions and keep the rest, which mainly contain small crypt pieces (Figure 3).

17. Pool the selected fractions in a $50 \mathrm{ml}$ Falcon tube and centrifuge the suspension at $55 \times \mathrm{g}$ for 5 min at $8{ }^{\circ} \mathrm{C}$.

Note: In the case reported in Figure 3, we would discard fraction 1 and pool fractions 2, 3 and 4.

18. Resuspend the pellet containing the crypts in pre-thawed Matrigel by gently pipetting 2-3 times using a P1000 micropipette and cold 1,000 $\mu$ pipette tips. The resuspension volume will depend on the number of eluted fractions pooled and therefore the size of the obtained pellet. For example, in the case reported in Figure 3, in which we have polled fractions 2, 3 and 4 (Figure $3 \mathrm{~A}$ ) and obtained the pellet of cells shown in Figure 3B we would use $500 \mu \mathrm{l}$ of Matrigel to resuspend the pellet.

Note: Thaw an aliquot $(1 \mathrm{ml})$ of Matrigel on ice at least $1 \mathrm{~h}$ before using it. At this step of the protocol you must work always on ice to prevent Matrigel from solidifying.

19. Pipette carefully a bubble-free $40 \mu \mathrm{l}$ drop of crypt-Matrigel suspension per well in a pre-warmed 24-well plate. Usually you will obtain around 15 drops. Place the plate into a $37{ }^{\circ} \mathrm{C}$ incubator for 5-10 min to let the Matrigel solidify.

Note: Place the 24-well plate into the incubator at $37^{\circ} \mathrm{C}$ for $10 \mathrm{~min}$ prior to seeding. This helps the drops to form properly.

A
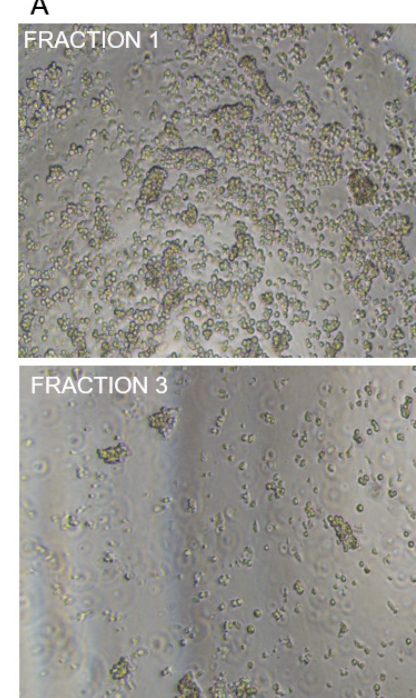

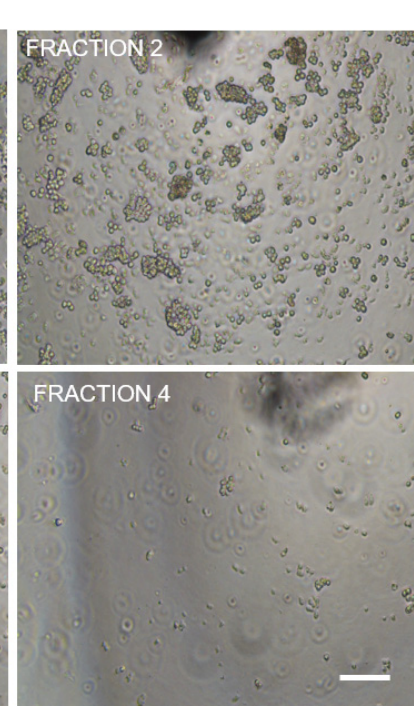

B

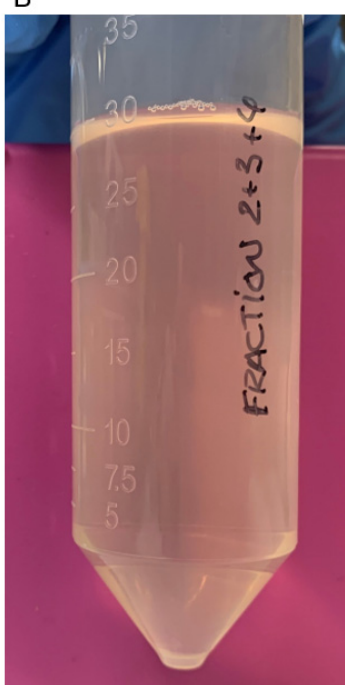

Figure 3. Elution process of the different crypt fractions. A. Bright field microscopy pictures showing 4 different crypt elution fractions of a given intestinal crypt isolation. Scale bar: $100 \mu \mathrm{m}$. B. Image showing the pellet of cells obtained from pooling crypt eluted fractions $2+3+4$ of the isolation shown in Figure 3A.

20. Add $400 \mu \mathrm{l}$ of the pre-warmed intestinal organoid growth medium (Table 1) into each well after Matrigel solidifies and transfer them back to the $37^{\circ} \mathrm{C}$ humidified incubator with $5 \% \mathrm{CO}_{2}$. 
21. Add extra ENR-CV factors (same concentration as in Table 1) every other day, in the current culture medium, during the first 4-5 days of the culture and Rho kinase inhibitor (Y-27632) (10 $\mu \mathrm{M})$ every day for the first 4 days to avoid epithelial cells death by anoikis. Change the whole medium every 2-3 days. Alternatively, add $100 \mu$ fresh medium every other day until passing of the organoids.

Note: Typically, crypts will start budding after 2-3 days in culture (Figure 4). Passage outgrow crypts after one week in culture. In case crypt confluence is very high, an earlier passage of the budding crypts will be required for a proper organoid formation. Typically, in the original drops we obtain around 100-125 organoids per drop.
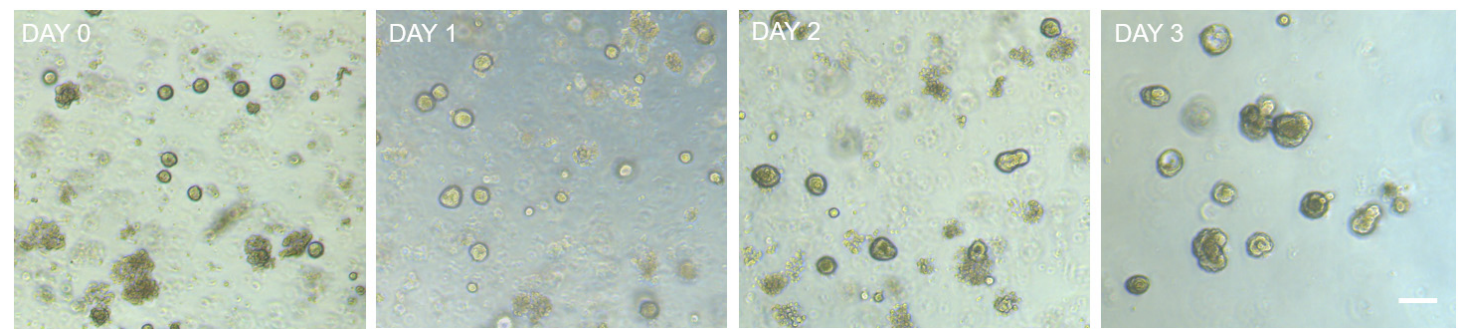

Figure 4. Bright field microscopy images showing the growth and budding of freshly isolated intestinal crypt over time (up to 3 days). Notice that intestinal crypts start to bud 23 days in culture after isolation. Scale bar: $100 \mu \mathrm{m}$.

B. Passaging crypts after organoid formation

1. Thaw Matrigel at least $1 \mathrm{~h}$ before the experiment by leaving the aliquots on ice.

2. Prepare and pre-warm the organoid growth medium (Table 1) and 24-well plates at $37^{\circ} \mathrm{C}$.

3. Remove the organoid growth media from the wells containing full-grown organoids (see Figure 5, left panels) add $300 \mu$ TrypLE Express $1 \mathrm{x}$ to each well and gently detach and disrupt the Matrigel drops by scraping it off using a P1000 micropipette. This step is performed at RT. Notes:

a. You can use $300 \mu$ TrypLE Express $1 x$ volume to recover organoids from 2 drops.

b. TrypLE Express $1 \mathrm{x}$ is used in this step to obtain crypts with more homogeneous size and favor Matrigel digestion.

4. Transfer the Matrigel suspension to a $15 \mathrm{ml}$ Falcon tube already placed on ice.

5. Pass the suspension through a $1 \mathrm{ml}$ syringe with a $23 \mathrm{G} 1$ " needle $3-4$ times to further mechanically disrupt the organoids. This step is performed on ice.

Note: The number of times you pass the sample through the syringe and the force you apply will depend on the size of the full-grown organoids you intend to break. Be aware that a too gentle procedure would not break the organoids and too harsh will over-digest the crypts.

6. Add $1 \mathrm{ml}$ of $2 \%$ FBS in PBS for every $300 \mu \mathrm{l}$ of suspension and agitate manually the tube to mix well the content.

Note: This step might be repeated in case a further wash is required.

7. Centrifuge at $72 \times g$ for $3 \mathrm{~min}$ at $8{ }^{\circ} \mathrm{C}$. 
8. Remove all the supernatant and resuspend the pellet in fresh Matrigel by gently pipetting using a micropipette. Resuspension volume will depend on the number of initial drops digested.

Note: Splitting ratio is usually 1:4-1:5.

9. Plate the Matrigel containing crypts drops (40 $\mu \mathrm{l} / \mathrm{drop})$ in pre-warmed 24-well plates as explained before.

10. Polymerize the Matrigel by incubating at $37^{\circ} \mathrm{C}$ for $5-10 \mathrm{~min}$.

11. Add $400 \mu \mathrm{l}$ of the intestinal organoid growth medium (Table 1) to each well and transfer the plate back to a $37^{\circ} \mathrm{C}$ humidified incubator with $5 \% \mathrm{CO}_{2}$

Note: See Figure 5 (middle panels) for a representative bright field microscope image of freshly dissociated intestinal organoid-derived crypts.
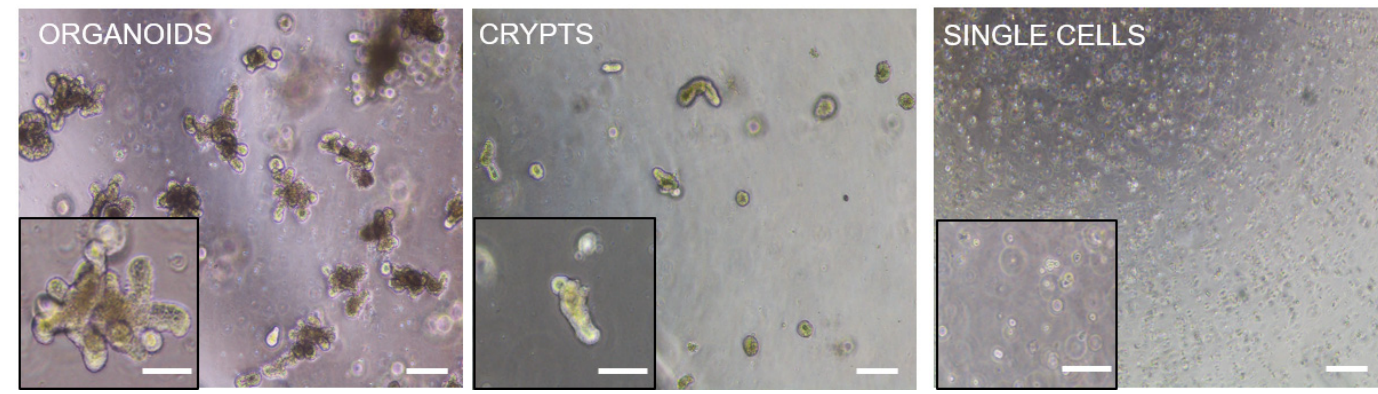

Figure 5. Representative bright field microscope images of full-grown intestinal organoids (left panels), freshly dissociated intestinal organoids-derived crypts (middle panels) and freshly digested intestinal organoids-derived single cells (right panels), grown in Matrigel drops. Insets show a magnification of the corresponding images. Please notice that due to the $3 \mathrm{D}$ culture not all cellular structures are in the same focus. Scale bars: $100 \mu \mathrm{m}, 50 \mu \mathrm{m}$ (inset).

C. Preparation of Matrigel-coated substrates

1. Place the ibidi 8-well $\mu$-Slides or Transwell inserts and P20 micropipette tips into the freezer beforehand.

Note: This step is especially important for obtaining homogeneous Matrigel coating.

2. Thaw Matrigel at least $1 \mathrm{~h}$ before the experiment by leaving the aliquots on ice.

3. Place the pre-cooled ibidi plate on ice. Pipette $10 \mu \mathrm{l}$ of Matrigel using a P20 micropipette and pre-cooled micropipettes in each of the ibidi plate wells or in each of the Transwell insert. Make sure that the $10 \mu \mathrm{l}$ of Matrigel are uniformly spread throughout the substrate surface by moving the pipette tip while releasing the Matrigel (see Video 1).

Note: Remove the excess Matrigel that accumulates at the Transwell insert border. 


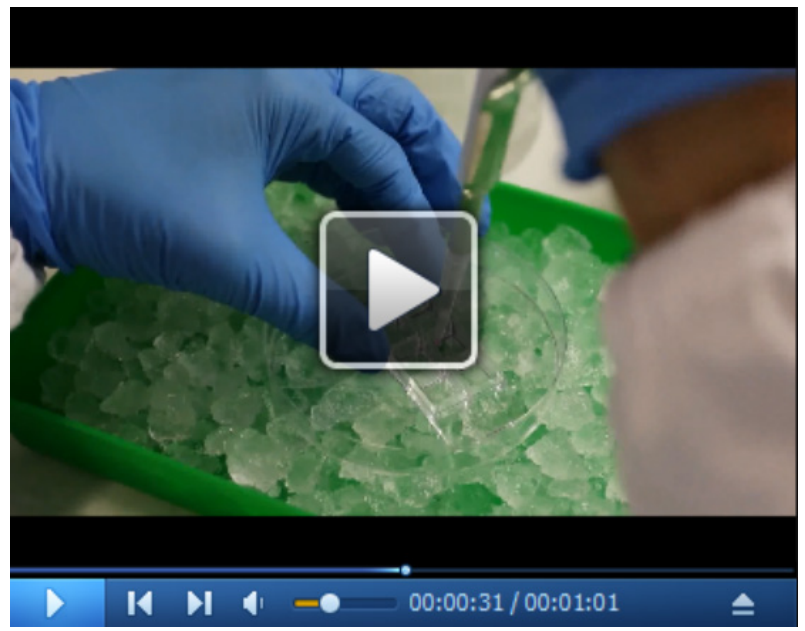

Video 1. Preparation of Matrigel-coated substrates

4. Repeat the Step C3 for all the wells and inserts required.

Note: Perform Steps C3 and C4 as fast as possible for a homogeneous coating.

5. Incubate the plates or inserts at $37^{\circ} \mathrm{C}$ for $1 \mathrm{~h}$ in the incubator to polymerize the Matrigel.

6. Continue with the seeding (see following Procedure D).

D. Generation of organoid-derived intestinal epithelial monolayers

1. Intestinal organoid-derived crypt seeding (Figure 1B)

a. Digest organoids to obtain crypts with homogeneous sizes as described in Steps B1-B6.

Note: See Figure 5 (middle panels) for a representative bright field microscope image of freshly dissociated intestinal organoid-derived crypts.

b. Mix well the Falcon containing the digested organoid suspension, take 3 times $5 \mu l$ samples using a P20 micropipette and place them into a Petri dish.

c. Count and average the number of crypt pieces within the $5 \mu$ volume using a bright field microscope and from that value estimate the total number of crypt pieces in the suspension.

d. Centrifuge to collect the crypt pieces at $72 \times g$ for 3 min at $4{ }^{\circ} \mathrm{C}$.

e. Resuspend the pellet in intestinal organoid growth medium (Recipe 1). Calculate the total medium volume needed for a seeding density of $1,500 \mathrm{crypts} / \mathrm{cm}^{2}$.

Notes:

i. $\quad$ The surface area of one well of ibidi 8-well $\mu$-Slides is $1 \mathrm{~cm}^{2}$. Then, the seeding density is 1,500 crypts/sample.

ii. For reference purposes, from one full-grown organoids Matrigel drop (Figure 5, left panels) we obtained approximately 1,000-1,500 crypts.

f. Pipette 30-50 $\mu \mathrm{l}$ of crypt suspension into each well of the Matrigel-coated ibidi 8-well $\mu$ Slides (see Procedure C). Try to place the sample as a drop in the center of the well.

g. Let the crypts attach to the substrate for 3-4 h and add $200 \mu \mathrm{l}$ more of intestinal organoid medium (Table 1). 
h. Change the medium every other day.

i. Inspect the monolayer formation and growth throughout the culture time using a bright field microscope. After seeding, organoid-derived crypts will rapidly refold on themselves to form crypt-like domains containing Lgr5 $5^{+}$intestinal stem cells $\left(\mathrm{GFP}^{+}\right)$. Then, cells spread on the substrate and migrate out of the crypt-like domains, forming epithelial monolayers composed on GFP- cells which correspond to the villus-like regions (Figure 6A).

2. Intestinal organoid-derived single cell seeding (Figure 1C)

a. Follow the organoids digestion protocol as described in Steps B1-B4.

b. Pass the suspension through $1 \mathrm{ml}$ syringe with a $23 \mathrm{G} 1$ " needle 5-6 times followed by a $5 \mathrm{~min}$ incubation at $37^{\circ} \mathrm{C}$. Agitate the cell suspension every minute to disrupt well the cell aggregates. After $5 \mathrm{~min}$ of incubation, place the sample on ice, pipette $5 \mu \mathrm{l}$ of the digestion on a Petri dish and inspect the sample under the microscope. If cell aggregates are still observed increase the incubation time $\left(37^{\circ} \mathrm{C}\right.$ ) for some more min (up to a total of $8 \mathrm{~min}$ ). Note: See Figure 5 (right panels) for a representative bright field microscope image of freshly digested intestinal organoid-derived single cells.

c. Once single cell suspension is achieved, place the tube on ice and add $1 \mathrm{ml}$ of PBS with $2 \%$ FBS for every $300 \mu$ l of suspension and agitate manually the tube to mix well the content. Note: This step might be repeated in case a further wash is required.

d. Count the number of cells in the suspension using a Neubauer counting chamber.

e. Centrifuge at $110 \times g$ for 4 min at $4{ }^{\circ} \mathrm{C}$.

f. Resuspend the pellet in organoid growth medium (Table 1). Calculate the total medium volume needed for a seeding density of $10^{5} \mathrm{cells} / \mathrm{cm}^{2}$.

Notes:

i. $\quad$ The surface area of one well of ibidi 8-well $\mu$-Slides is $1 \mathrm{~cm}^{2}$. Then, the seeding density is $10^{5}$ cells/sample.

ii. For reference purposes, from one full-grown organoids Matrigel drop (Figure 5, left panels) we obtained approximately $1.5 \times 10^{5}-1.7 \times 10^{5}$ single cells.

g. Seed the Matrigel-coated ibidi 8-well $\mu$-Slides (see Procedure C) with 10-20 $\mu$ of single cell suspension.

Note: Place the single cell suspension drop into the center of the well and be careful to not to disrupt it.

h. Let the cells attach for $1 \mathrm{~h}$, add $200 \mu \mathrm{l}$ more of intestinal organoid medium (Table 1 ) plus Rho kinase inhibitor Y-27632 at $10 \mu \mathrm{M}$ final concentration.

i. Change the medium every other day.

j. Inspect the monolayer formation and growth using a bright field microscope. After seeding, organoid-spontaneously self-assemble to form crypt-like domains containing $\mathrm{Lgr5}^{+} \mathrm{ISCs}$, closely mimicking the in vivo arrangement at the crypt bases. Then, cells start to spread out generating epithelial monolayers composed of GFP- giving rise to the villus-like regions (Figure 6B). 

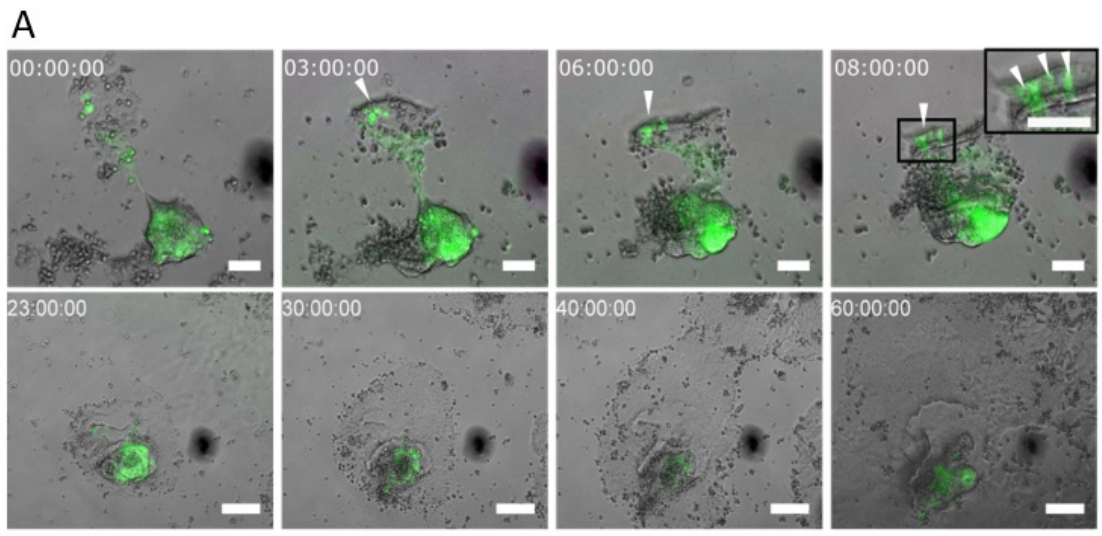

B
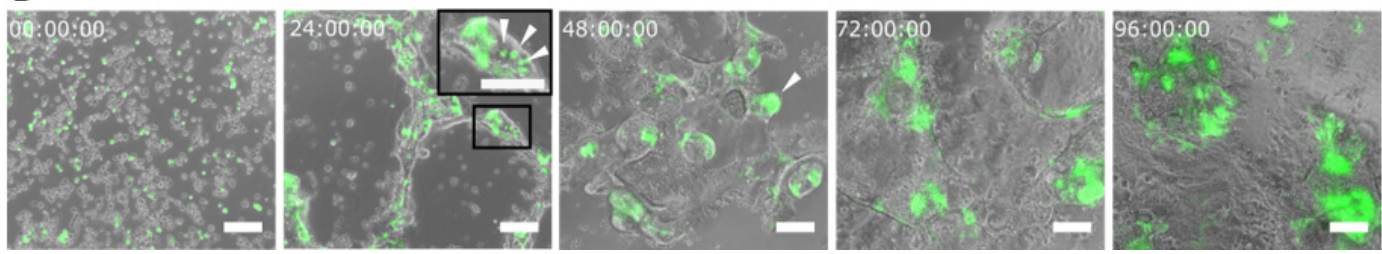

Figure 6. Stem cells self-assemble in crypt-like domains and originate epithelial monolayers. (A) Live-imaging sequence of overlapped bright field and GFP signal corresponding to 60 hours after seeding organoid-derived crypts and (B) 96 hours after seeding organoid-derived single cells on a thin film of Matrigel. The corresponding time for each snapshot is shown in each panel. White arrow heads indicate Lgr5-GFP ${ }^{+}$cells. Scale bars: $50 \mu \mathrm{m}$ (A, upper row) and $100 \mu \mathrm{m}$ (A, lower row, and B). Figure adapted from the original publication (Altay et al., 2019, under Creative Commons Attribution 4.0 International License, http://creativecommons.org/licenses/by/4.0/).

E. Intestinal subepithelial myofibroblast isolation and culture

1. Collect the tissue left from the crypt digestion and elution described in Step A15.

2. Add $10 \mathrm{ml}$ of $3 \mathrm{mM}$ EDTA in PBS and incubate for $10 \mathrm{~min}$ at $37^{\circ} \mathrm{C}$ and $200 \mathrm{rpm}$ in an incubated benchtop orbital shaker.

Note: Pre-warm the EDTA solution to $37^{\circ} \mathrm{C}$.

3. After incubation, let the pieces settle down and discard the supernatant. Repeat Step E2 two more times.

4. Discard the supernatant and rinse the pellet with $20 \mathrm{ml}$ of PBS. Repeat this step 2 times more. Note: This step is important to remove all EDTA.

5. Discard the supernatant and add intestinal epithelial myofibroblast digestion medium (Table 2).

6. Incubate for $40 \mathrm{~min}$ in an incubated benchtop orbital shaker at $37^{\circ} \mathrm{C}$ and $200 \mathrm{rpm}$.

7. After the incubation, pipette the suspension up and down during $1 \mathrm{~min}$ using $10 \mathrm{ml}$ pipette.

8. Centrifuge at $160 \times g$ for $5 \mathrm{~min}$.

9. Resuspend the pellet with $10 \mathrm{ml}$ of ACK lysing Buffer (pre-warmed at $47^{\circ} \mathrm{C}$ ).

10. Centrifuge at $160 \times g$ for $5 \mathrm{~min}$.

11. Resuspend the pellet with $10 \mathrm{ml}$ intestinal epithelial myofibroblast culture medium (Table 3 ) and 
culture in $25 \mathrm{~cm}^{2}$ cell culture flask.

Note: Tissue pieces will eventually attach to the flask and myofibroblasts will grow out and spread though the flask. Replace the medium every 3-4 days. Usually, 2-3 weeks after isolation flask will be confluent. Figure 7 shows representative bright field microscopy images of this process.

12. Cell are passaged by normal trypsinization for 5 min. Splitting ration 1:3.
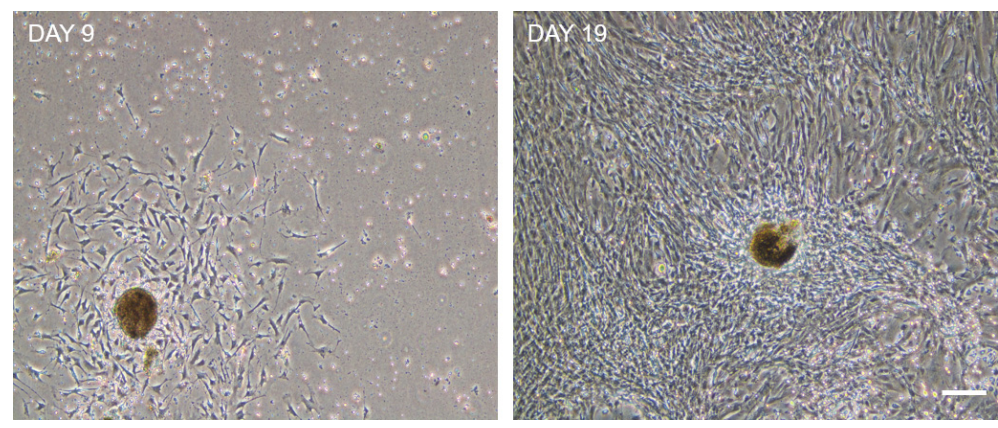

Figure 7. Representative bright field microscopy images of ISEMF growth on tissue culture flasks at day 9 (left panel) and day 19 (right panel) after seeding. Notice that digested tissue pieces attach to the plastic and emerging fibroblast spread through the flask until reaching confluence. This process might take 21 days. Scale bar: $200 \mu \mathrm{m}$.

F. Intestinal subepithelial myofibroblast conditioned medium (ISEMF_CM) production

1. Grow $60-80 \%$ confluent ISEMF cultures for $4-6$ days without changing the medium (Figure 8).

2. Harvest the medium and centrifuge it at $160 \times g$ for $5 \mathrm{~min}$ to remove debris.

Note: Add fresh intestinal epithelial myofibroblast culture medium (Table 3) to the plates and continue the culture. Passage the cells if required (Step E12).

3. Collect the supernatant and filter it using a $0.22 \mu \mathrm{m}$ pore size filter and a $10 \mathrm{ml}$ syringe.

4. Store the filtered ISEMF_CM at $-80^{\circ} \mathrm{C}$ until use.

5. Repeat Steps F1-F4 until cells become senescent (usually after 5-6 passages).

6. Pool all ISEMF_CM fraction collected from the same ISEMF isolation and prepare the boosting medium as described in Table 4.

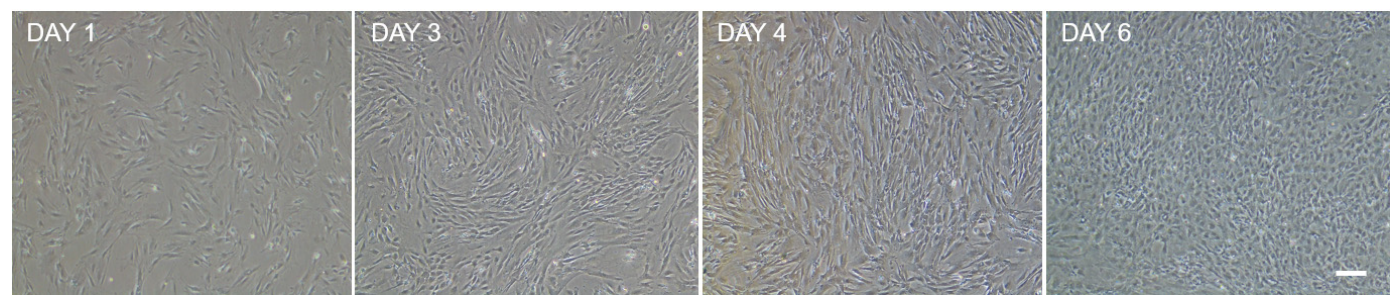

Figure 8. Bright field microscopy images showing the growth of ISEMF during 6 days after splitting. ISEMF_CM is collected during this period when ISEMF confluence is around 60 to $80 \%$. 
G. Evaluating the epithelial monolayer formation and barrier integrity with transepithelial electrical resistance (TEER) measurements

1. Prepare Matrigel-coated Transwell inserts as explained in Procedure C.

2. Follow the steps described in Step D1a until Step D1d to dissociate the organoids to crypts.

3. Resuspend the pellet in basic-medium (Table 5). Calculate the total medium volume needed for a seeding density of $3,000-3,500 \mathrm{crypts} / \mathrm{cm}^{2}$.

Notes:

a. The surface area of one $6.5 \mathrm{~mm}$ diameter Transwell insert is $0.33 \mathrm{~cm}^{2}$.

b. For reference purposes, from one full-grown organoids Matrigel drop (Figure 5, left panels) we obtained approximately 1,000-1,500 crypts.

4. Seed each of the Matrigel-coated Transwell inserts with 30-50 $\mu \mathrm{l}$ of crypt suspension.

Note: Leave 2-3 Matrigel-coated Transwell inserts without seeding as controls for TEER measurements.

5. Let the crypts attach for $1-2 \mathrm{~h}$ and add $200 \mu \mathrm{l}$ more of basic-medium (Table 5) at the apical (upper) side of the Transwell.

6. Prepare the boosting medium (Table 4) and add $500 \mu \mathrm{l}$ to the basolateral (bottom) side of the Transwell.

7. Add the corresponding medium to the control (no cells) inserts as well.

8. Place the plate in a $37{ }^{\circ} \mathrm{C}$ humidified incubator with $5 \% \mathrm{CO}_{2}$. Change the medium of both apical and basolateral sides every other day.

9. After changing medium, let the plate under the hood at RT for 5-10 min so that the medium temperature equilibrates.

10. In the meanwhile, sterilize the EVOM2 epithelial voltohmmeter STX3 electrodes by submerging them into $70 \%$ Ethanol (Table 6) for 15 min.

11. Rinse the electrodes with PBS and keep them in the solution until starting the measurements.

12. Turn on the voltohmmeter, plug the electrodes and introduce one to the apical and the other to the basolateral side of the Transwell. Record the value measured.

13. Remove the electrodes and reinsert to measure again. Repeat this step one more time to obtain 3 different measurements from the same sample.

14. Wash the electrodes in between measurements by submerging into PBS and then into basic medium.

15. After finishing the measurements, sterilize the electrodes by submerging them into $70 \%$ Ethanol for $15 \mathrm{~min}$. Rinse them with sterile Milli-Q, let them air-dry under the cell culture hood and store.

16. Measure the TEER of the monolayers every 2 days, up to 20 days of culture.

17. Calculate the electrical resistance corresponding to epithelial monolayers by subtracting the intrinsic resistance (values measured on control samples without cells) from the total resistance measured (samples with the cells) and corrected for surface area $\left(0.33 \mathrm{~cm}^{2}\right)$ expressed as $\mathrm{ohm} \cdot \mathrm{cm}^{2}$. 
Note: For reference purposes, TEER values progressively increase up to approximately 60 ohms $\cdot \mathrm{cm}^{2}$ after 20 days in culture.

\section{Data analysis}

For statistical comparison, we used two-tailed, unequal variance t-test and we considered $P<0.05$ to be significant. We repeated monolayer formation protocol in at least three independent experiments. We performed three independent experiments with two technical replicas per condition per experiment for TEER measurements. The detailed explanation of data analysis performed, can be found in the Materials and Methods, and Supplementary Information sections of the original article (Altay et al., 2019). 


\section{Recipes}

1. Intestinal organoid growth medium or ENR_CV medium

Table 1. Component list for the formulation of the intestinal organoid growth medium or ENR_CV medium. Stock and final concentration are indicated, as well as the solvent employed (when required). Volumes for each of the components (at stock concentration) for a final volume of $20 \mathrm{ml}$ of medium are shown.

\begin{tabular}{|c|c|c|c|c|}
\hline Reagent & $\begin{array}{l}\text { Stock } \\
\text { concentration }\end{array}$ & $\begin{array}{l}\text { Stock } \\
\text { solvent }\end{array}$ & $\begin{array}{l}\text { For } 20 \mathrm{ml} \text { final volume } \\
\text { (use immediately) }\end{array}$ & $\begin{array}{l}\text { Final } \\
\text { concentration }\end{array}$ \\
\hline Glutamax & $100 x$ & & $200 \mu \mathrm{l}$ & $1 \% \mathrm{v} / \mathrm{v}$ \\
\hline HEPES & $1 \mathrm{M}$ & & $200 \mu \mathrm{l}$ & $1 \% \mathrm{v} / \mathrm{v}(10 \mathrm{mM})$ \\
\hline Normocin & $50 \mathrm{mg} / \mathrm{ml}$ & & $40 \mu \mathrm{l}$ & $100 \mu \mathrm{g} / \mathrm{ml}$ \\
\hline B-27 & $50 x$ & & $400 \mu \mathrm{l}$ & $2 \% \mathrm{v} / \mathrm{v}$ \\
\hline $\mathrm{N}-2$ & $100 x$ & & $200 \mu \mathrm{l}$ & $1 \% \mathrm{v} / \mathrm{v}$ \\
\hline $\begin{array}{l}\mathrm{N}-\text { Acetyl-L- } \\
\text { cysteine }\end{array}$ & $500 \mathrm{mM}$ & Milli-Q & $50 \mu \mathrm{l}$ & $1.25 \mathrm{mM}$ \\
\hline Advanced & & & $18,910 \mu \mathrm{l}$ & \\
\hline \multicolumn{5}{|l|}{ DMEM/F12 } \\
\hline EGF & $100 \mu \mathrm{g} / \mathrm{ml}$ & PBS & $20 \mu l$ & $100 \mathrm{ng} / \mathrm{ml}$ \\
\hline Noggin & $100 \mu \mathrm{g} / \mathrm{ml}$ & PBS & $20 \mu \mathrm{l}$ & $100 \mathrm{ng} / \mathrm{ml}$ \\
\hline R-Spondin 1 & $100 \mu \mathrm{g} / \mathrm{ml}$ & PBS & $40 \mu \mathrm{l}$ & $200 \mathrm{ng} / \mathrm{ml}$ \\
\hline CHIR99021 & $10 \mathrm{mM}$ & DMSO & $6 \mu \mathrm{l}$ & $3 \mu \mathrm{M}$ \\
\hline Valproic acid & $1 \mathrm{M}$ & Milli-Q & $20 \mu \mathrm{l}$ & $1 \mathrm{mM}$ \\
\hline
\end{tabular}

2. Intestinal subepithelial myofibroblast digestion medium 
Table 2. Component list for the formulation of the intestinal subepithelial myofibroblast digestion medium. Stock and final concentration are indicated, as well as the solvent employed (when required). Volumes for each of the components (at stock concentration) for a final volume of $20 \mathrm{ml}$ of medium are shown.

$\left.\begin{array}{lllll}\hline \text { Reagent } & \begin{array}{l}\text { Stock } \\ \text { concentration }\end{array} & \begin{array}{l}\text { Stock } \\ \text { solvent }\end{array} & \begin{array}{l}\text { For } 20 \mathrm{ml} \text { final volume (use } \\ \text { immediately) }\end{array} & \begin{array}{l}\text { Final } \\ \text { concentration }\end{array} \\ \hline \text { FBS } & & 4,000 \mu \mathrm{l} & 20 \% \mathrm{v} / \mathrm{v} \\ \text { Collagenase } & 100 \mathrm{mg} / \mathrm{ml} & \text { PBS } & 75 \mu \mathrm{l} & 0.37 \mathrm{mg} / \mathrm{ml}(100 \\ & & & \mathrm{U} / \mathrm{ml})\end{array}\right)$

Add the enzyme just before using the medium.

3. Intestinal subepithelial myofibroblast culture medium

Table 3. Component list for the formulation of the intestinal subepithelial myofibroblast culture medium. Stock and final concentration are indicated, as well as the solvent employed (when required). Volumes for each of the components (at stock concentration) for a final volume of $20 \mathrm{ml}$ of medium are shown.

\begin{tabular}{llll}
\hline Reagent & $\begin{array}{l}\text { Stock } \\
\text { concentration }\end{array}$ & $\begin{array}{l}\text { For } \mathbf{2 0 ~} \mathrm{ml} \text { final volume (store } \\
\text { at } \mathbf{2 - 8}{ }^{\circ} \mathbf{C} \text { up to } 2 \text { weeks) }\end{array}$ & Final concentration \\
\hline FBS & $2,000 \mu \mathrm{l}$ & $10 \% \mathrm{v} / \mathrm{v}$ \\
$\begin{array}{l}\text { Penicillin- } \\
\text { streptomycin }\end{array}$ & $100 \mathrm{x}$ & $200 \mu \mathrm{l}$ & $1 \% \mathrm{v} / \mathrm{v}$ \\
MEM-NEA & $100 \mathrm{x}$ & & $1 \% \mathrm{v} / \mathrm{v}$ \\
Normocin & $50 \mathrm{mg} / \mathrm{ml}$ & $40 \mu \mathrm{l}$ & $100 \mu \mathrm{g} / \mathrm{ml}$ \\
DMEM & & $17,560 \mu \mathrm{l}$ & \\
\hline
\end{tabular}


4. Boosting medium

Table 4. Components list for the formulation of the boosting medium. Stock and final concentration are indicated, as well as the solvent employed (when required). Volumes for each of the components (at stock concentration) for a final volume of $20 \mathrm{ml}$ of medium are shown.

\begin{tabular}{|c|c|c|c|c|}
\hline Reagent & $\begin{array}{l}\text { Stock } \\
\text { concentration }\end{array}$ & $\begin{array}{l}\text { Stock } \\
\text { solvent }\end{array}$ & $\begin{array}{l}\text { For } 20 \mathrm{ml} \text { final volume } \\
\text { (use immediately) }\end{array}$ & $\begin{array}{l}\text { Final } \\
\text { concentration }\end{array}$ \\
\hline Glutamax & $100 x$ & & $200 \mu \mathrm{l}$ & $1 \% \mathrm{v} / \mathrm{v}$ \\
\hline HEPES & $1 \mathrm{M}$ & & $200 \mu \mathrm{l}$ & $1 \% \mathrm{v} / \mathrm{v}(10 \mathrm{mM})$ \\
\hline Normocin & $50 \mathrm{mg} / \mathrm{ml}$ & & $40 \mu \mathrm{l}$ & $100 \mu \mathrm{g} / \mathrm{ml}$ \\
\hline B-27 & $50 x$ & & $400 \mu \mathrm{l}$ & $2 \% \mathrm{v} / \mathrm{v}$ \\
\hline $\mathrm{N}-2$ & $100 x$ & & $200 \mu \mathrm{l}$ & $1 \% \mathrm{v} / \mathrm{v}$ \\
\hline $\begin{array}{l}\text { N-Acetyl-L- } \\
\text { cysteine }\end{array}$ & $500 \mathrm{mM}$ & Milli-Q & $50 \mu \mathrm{l}$ & $1.25 \mathrm{mM}$ \\
\hline ISEMF_CM & & & $18,910 \mu \mathrm{l}$ & \\
\hline EGF & $100 \mu \mathrm{g} / \mathrm{ml}$ & PBS & $20 \mu \mathrm{l}$ & $100 \mathrm{ng} / \mathrm{ml}$ \\
\hline Noggin & $100 \mu \mathrm{g} / \mathrm{ml}$ & PBS & $20 \mu \mathrm{l}$ & $100 \mathrm{ng} / \mathrm{ml}$ \\
\hline R-Spondin 1 & $100 \mu \mathrm{g} / \mathrm{ml}$ & PBS & $40 \mu \mathrm{l}$ & $200 \mathrm{ng} / \mathrm{ml}$ \\
\hline CHIR99021 & $10 \mathrm{mM}$ & DMSO & $6 \mu \mathrm{l}$ & $3 \mu \mathrm{M}$ \\
\hline Valproic acid & $1 \mathrm{M}$ & Milli-Q & $20 \mu \mathrm{l}$ & $1 \mathrm{mM}$ \\
\hline Wnt3a & $100 \mu \mathrm{g} / \mathrm{ml}$ & Milli-Q & $5 \mu l$ & $25 \mathrm{ng} / \mathrm{ml}$ \\
\hline
\end{tabular}

If not prepared fresh, this medium (without adding the ENR_CV and Wnt3a factor) can be stored at $2-8{ }^{\circ} \mathrm{C}$ up to 2 weeks. ENR_CV and Wnt3a factor must be added just before used.

5. Basic-medium 
Table 5. Components list for the formulation of the basic-medium. Stock and final concentration are indicated, as well as the solvent employed (when required). Volumes for each of the components (at stock concentration) for a final volume of $20 \mathrm{ml}$ of medium are shown.

\begin{tabular}{lllll}
\hline Reagent & $\begin{array}{l}\text { Stock } \\
\text { concentration }\end{array}$ & $\begin{array}{l}\text { Stock } \\
\text { solvent }\end{array}$ & $\begin{array}{l}\text { For } \mathbf{2 0 ~ m l ~ f i n a l ~ v o l u m e ~ ( s t o r e ~} \\
\text { at } \mathbf{2 - 8}{ }^{\circ} \mathbf{C} \text { up to 2 weeks) }\end{array}$ & $\begin{array}{l}\text { Final } \\
\text { concentration }\end{array}$ \\
\hline Glutamax & $100 \mathrm{x}$ & $200 \mu \mathrm{l}$ & $1 \% \mathrm{v} / \mathrm{v}$ \\
HEPES & $1 \mathrm{M}$ & $200 \mu \mathrm{l}$ & $1 \% \mathrm{v} / \mathrm{v}(10 \mathrm{mM})$ \\
Normocin & $50 \mathrm{mg} / \mathrm{ml}$ & $40 \mu \mathrm{l}$ & $100 \mu \mathrm{g} / \mathrm{ml}$ \\
B-27 & $50 \mathrm{x}$ & $400 \mu \mathrm{l}$ & $2 \% \mathrm{v} / \mathrm{v}$ \\
$\mathrm{N}-2$ & $100 \mathrm{x}$ & $200 \mu \mathrm{l}$ & $1 \% \mathrm{v} / \mathrm{v}$ \\
$\mathrm{N}-$-Acetyl-L- & $500 \mathrm{mM}$ & Milli-Q & $50 \mu \mathrm{l}$ & $1.25 \mathrm{mM}$ \\
cysteine & & & $18,910 \mu \mathrm{l}$ \\
\hline $\begin{array}{l}\text { Advanced } \\
\text { DMEM/F12 }\end{array}$ & & & \\
\hline
\end{tabular}

6. $70 \% \mathrm{v} / \mathrm{v}$ Ethanol

Table 6. Components list for the preparation of $70 \% \mathrm{v} / \mathrm{v}$ Ethanol. Volumes for each of the components (at stock concentration) for a final volume of $1 \mathrm{~L}$ are shown.

\begin{tabular}{llll}
\hline Reagent & $\begin{array}{l}\text { Stock } \\
\text { concentration }\end{array}$ & $\begin{array}{l}\text { For 1 L final volume (store at } \\
\text { RT) }\end{array}$ & Final concentration \\
\hline Ethanol & $96 \% \mathrm{v} / \mathrm{v}$ & $230 \mathrm{ml}$ & $70 \% \mathrm{v} / \mathrm{v}$ \\
Milli-Q & & $770 \mathrm{ml}$ & \\
\hline
\end{tabular}

\section{Acknowledgments}

Funding for this project was provided by European Union's Horizon 2020 ERC grant agreement No 647863 (COMIET), the CERCA Programme/Generalitat de Catalunya (2017-SGR-1079), and the Spanish Ministry of Economy and Competitiveness (TEC2017-83716-C2-1-R and the Severo Ochoa Program for Centers of Excellence in R\&D 2016-2019). The authors gratefully acknowledge the Agència de Gestió d'Ajuts Universitaris i de Recerca (AGAUR) for the funding of Gizem Altay through FI-DGR 2014. The results presented here reflect only the views of the authors; the European Commission is not responsible for any use that may be made of the information it contains. This protocol is adapted from the method published in Altay et al., 2019. We kindly thank 
the staff from the IBEC communication department for their assistance in the video recording and editing.

\section{Competing interests}

The authors declare no financial or non-financial competing interests.

\section{Ethics}

All experimental protocols involving mice were approved by the Animal care and Use Committee of Barcelona Science Park (CEEA-PCB) and the Catalan government and performed in accordance to their relevant guidelines and regulations. Approval ID of the experimentation project: 9162 , validity period: 12/2018-12/2023.

\section{$\underline{\text { References }}$}

1. Altay, G., Larrañaga, E., Tosi, S., Barriga, F. M., Batlle, E., Fernández-Majada, V. and Martínez, E. (2019). Self-organized intestinal epithelial monolayers in crypt and villus-like domains show effective barrier function. Sci Rep 9(1): 10140.

2. Ettayebi, K., Crawford, S. E., Murakami, K., Broughman, J. R., Karandikar, U., Tenge, V. R., Neill, F. H., Blutt, S. E., Zeng, X. L., Qu, L., Kou, B., Opekun, A. R., Burrin, D., Graham, D. Y., Ramani, S., Atmar, R. L. and Estes, M. K. (2016). Replication of human noroviruses in stem cell-derived human enteroids. Science 353(6306): 1387-1393.

3. In, J., Foulke-Abel, J., Zachos, N. C., Hansen, A. M., Kaper, J. B., Bernstein, H. D., Halushka, M., Blutt, S., Estes, M. K., Donowitz, M. and Kovbasnjuk, O. (2016). Enterohemorrhagic Escherichia coli reduce mucus and intermicrovillar bridges in human stem cell-derived colonoids. Cell Mol Gastroenterol Hepatol 2(1): 48-62 e43.

4. Kozuka, K., He, Y., Koo-McCoy, S., Kumaraswamy, P., Nie, B., Shaw, K., Chan, P., Leadbetter, M., He, L., Lewis, J. G., Zhong, Z., Charmot, D., Balaa, M., King, A. J., Caldwell, J. S. and Siegel, M. (2017). Development and characterization of a human and mouse intestinal epithelial cell monolayer platform. Stem Cell Reports 9(6): 1976-1990.

5. Liu, Y., Qi, Z., Li, X., Du, Y. and Chen, Y. G. (2018). Monolayer culture of intestinal epithelium sustains Lgr ${ }^{5+}$ intestinal stem cells. Cell Discov 4: 32.

6. Moon, C., VanDussen, K. L., Miyoshi, H. and Stappenbeck, T. S. (2014). Development of a primary mouse intestinal epithelial cell monolayer culture system to evaluate factors that modulate IgA transcytosis. Mucosal Immunol 7(4): 818-828.

7. Ootani, A., Li, X., Sangiorgi, E., Ho, Q. T., Ueno, H., Toda, S., Sugihara, H., Fujimoto, K., Weissman, I. L., Capecchi, M. R. and Kuo, C. J. (2009). Sustained in vitro intestinal epithelial culture within a Wnt-dependent stem cell niche. Nat Med 15(6): 701-706. 
8. Sato, T., Vries, R. G., Snippert, H. J., van de Wetering, M., Barker, N., Stange, D. E., van Es, J. H., Abo, A., Kujala, P., Peters, P. J. and Clevers, H. (2009). Single Lgr5 stem cells build cryptvillus structures in vitro without a mesenchymal niche. Nature 459(7244): 262-265.

9. Thorne, C. A., Chen, I. W., Sanman, L. E., Cobb, M. H., Wu, L. F. and Altschuler, S. J. (2018). Enteroid monolayers reveal an autonomous WNT and BMP circuit controlling intestinal epithelial growth and organization. Dev Cell 44(5): 624-633 e624.

10. VanDussen, K. L., Marinshaw, J. M., Shaikh, N., Miyoshi, H., Moon, C., Tarr, P. I., Ciorba, M. A. and Stappenbeck, T. S. (2015). Development of an enhanced human gastrointestinal epithelial culture system to facilitate patient-based assays. Gut 64(6): 911-920.

11. Wang, Y., DiSalvo, M., Gunasekara, D. B., Dutton, J., Proctor, A., Lebhar, M. S., Williamson, I. A., Speer, J., Howard, R. L., Smiddy, N. M., Bultman, S. J., Sims, C. E., Magness, S. T. and Allbritton, N. L. (2017a). Self-renewing Monolayer of Primary Colonic or Rectal Epithelial Cells. Cell Mol Gastroenterol Hepatol 4(1): 165-182 e167.

12. Wang, Y., Gunasekara, D. B., Reed, M. I., DiSalvo, M., Bultman, S. J., Sims, C. E., Magness, S. T. and Allbritton, N. L. (2017b). A microengineered collagen scaffold for generating a polarized crypt-villus architecture of human small intestinal epithelium. Biomaterials 128: 44-55. 